\title{
Economía e intensificación agrícola: variabilidad en trayectorias de cambio agrícola en la América Prehispánica
}

\author{
Economy and agricultural intensification: \\ variability in trajectories of agricultural change in Prehispanic \\ America
}

(iD) Juan Carlos Vargas Ruiz ${ }^{1}$

En memoria de la gran Denisse Schaan, inspiración para una generación de arqueólogos en Suramérica.

\begin{abstract}
Resumen
El paso de una economía de subsistencia a una economía política ha sido considerado como una de las transformaciones fundamentales para el surgimiento de sociedades complejas. El desarrollo de estrategias agrícolas intensivas, que permitió la acumulación de excedentes, se ha argumentado que fue una condición necesaria para la aparición de jerarquías regionales en distintas partes del mundo. Una de las principales evidencias que los arqueólogos han usado para demostrar la relación entre agricultura y el surgimiento de la desigualdad social ha sido el paisaje, el cual ha sido modificado mediante la implementación de estructuras a través del tiempo por las sociedades humanas alrededor del mundo. La elaboración de terrazas, campos elevados y sistemas hidráulicos para el cultivo, ha sido relacionada con procesos de intensificación económica y organización política centralizada. Este artículo presenta una discusión a partir de la revisión de los modelos arqueológicos de economía política en los que la construcción de estructuras para la producción de excedentes alimentarios fue crítica para el surgimiento de desigualdad social. Para esto se presenta un análisis comparativo de distintos casos de sociedades complejas provenientes de Colombia y otras regiones de América, entre los que se encuentran los Llanos de Casanare y la región Calima; la región del Valle Black Warrior (Mississippi - Estados Unidos); los Llanos de Moxos (Bolivia), la Isla de Marajo (Brasil), la región de Yaguachi (Ecuador) y los Llanos de Barinas (Venezuela). Se plantea que, así como arqueológicamente se han identificado distintas trayectorias de cambio social en el pasado, también existieron distintas trayectorias de cambio agrícola, las cuales guardan relación con el surgimiento de desigualdad y complejidad social.
\end{abstract}

Palabras clave: cambio agrícola; sociedades complejas; arqueología del paisaje.

Tipología: Artículo de investigación

Recibido: 25/03/2019

Evaluado: $25 / 04 / 2019$

Aceptado: 29/04/2019

Disponible en línea: 02/05/2019

Cómo citar este artículo: Vargas Ruiz, J. (2019) Economía e intensificación agrícola: variabilidad en trayectorias de cambio agrícola en la América Prehispánica. Jangwa Pana, 18 (2), 232-255. Doi: http://dx.doi.org/10.21676/16574923.2927

${ }^{1}$ Antropólogo M.Sc., Ph.D. Docente investigador. Programa de Antropología. Universidad del Magdalena. ORCID ID: 0000-0002-7933-629X. Correo electrónico: jvargasr@ unimagdalena.edu.co 


\begin{abstract}
The transition from subsistence economy to political economy has been recognized as one of the main transformations leading to the emergence of social complexity. The development of intensive agricultural strategies was critical for surplus accumulation as a first necessary step for the emergence of regional hierarchies. Landscapes are one of the main evidence used by archaeologists in order to demonstrate the relationship between agriculture and the emergence of social inequality worldwide. The construction of terraces, raised fields, and other kinds of facilities for cultivation, has been related by the archaeologists to the processes of economic intensification and the emergence of centralized political organization. This paper aims to present a discussion of several archaeological models in which the construction of structures for the production of food surpluses was critical for the emergence of social inequality. To achieve this goal, a comparative analysis is presented here, based on the archaeological record of the complex societies from the Calima region and the Llanos of Casanare (Colombia); the Black Warrior Valley (Mississippi) in the southeast of North America; and from the Llanos of Moxos (Bolivia), the Marajo Island (Brasil), the Yaguachi region (Ecuador) and the Llanos of Barinas (Venezuela). The main argument of this paper is that just as there were many different pathways to social change in the past, there were also different trajectories of agricultural change that could be related to the emergence of inequality and social complexity.
\end{abstract}

Keywords: Agricultural change; complex societies; landscape archaeology.

\section{Introducción: Las trayectorias de cambio agrícola vistas desde los modelos teóricos en arqueología}

El direccionamiento de la producción de excedentes agrícolas es fundamental para la transición de una economía de subsistencia a una economía política y el posterior desarrollo de las jerarquías cacicales en los grupos humanos (Brumfiel y Earle, 1987; Carneiro, 1970, 1998; Clark y Blake, 1994; Cobb, 1996; D’Altroy y Earle, 1985; Drennan, 1995; Earle, 1997; Gilman, 2001; Hayden, 1995; Morrison, 1994; Nicholas, 1989; Spencer, 1993; Stanish, 2004; Stone, 1996).

Hay dos posiciones contradictorias sobre la articulación de la economía de subsistencia y la economía política con respecto a la intensificación agrícola. Los modelos de arriba hacia abajo conciben el proceso de intensificación como resultado del estímulo y la gestión de la élite (Clark y Blake, 1994; Earle, 1997; Gilman, 2001; Kirch, 2006; Spencer, 1993; Stanish, 2001). Desde este punto de vista, los agricultores son incapaces de generar excedentes a menos que sean forzados por la élite gobernante. La agencia en los modelos que asumen un enfoque desde arriba hacia abajo (top-down) a menudo atribuyen a la élite todo el agenciamiento para realizar cambios, mientras que sus seguidores permanecen pasivos (Erickson, 2006; Scarborough, 2006; Thurston, 2006).

Por otra parte, se considera que la construcción de sistemas a gran escala no requiere necesariamente la gestión de una autoridad centralizada (Erickson, 2006). La visión desde abajo hacia arriba (bottom-up) sugiere que las comunidades de pequeña escala, compuestas por pequeños agricultores, pueden construir estructuras de intensificación agrícola de gran escala y generar suficientes excedentes (Erickson, 1993, 2006; Netting, 1990; Scarborough, 2006). La gran movilización de trabajo y la inversión de recursos pueden ser desarrolladas por pequeñas comunidades agrícolas, que son capaces de planificar y mantener esquemas complicados y laboriosos de intensificación agrícola mediante la implementación de estructuras agrícolas de gran 
envergadura sin la presencia de una autoridad central.

Brookfield (1984) ha argumentado que las sociedades humanas realizaban modificaciones medioambientales por medio de la aplicación de fuerza de trabajo, de tal forma que el paisaje que se observa en bastantes regiones alrededor del mundo es el resultado de la manufactura humana, manifestada en la presencia de antrosoles, canales, campos elevados, terrazas, etc., que permitieron incrementar la productividad de la tierra, mientras creaban palimpsestos que respondían a las necesidades y expectativas de sus constructores. A esta forma de acumulación de recursos y trabajo, Brookfield (1984) lo denominó como capital landesque, que, desde su perspectiva, era una inversión que garantizaba la producción agrícola a futuro. Este capital acumulado en la tierra puede ser transferido de generación en generación, por lo cual su transmisión y propiedad resulta ser de gran importancia en términos del desarrollo de sistemas inequitativos y jerárquicos, teniendo en cuenta los elementos de la economía política anteriormente discutidos.

Earle y Doyel (2008) han planteado que una forma de capital landesque son los paisajes con ingeniería (no pude encontrar una mejor traducción para engineered landscapes) o con infraestructura agrícola (Stone 1996), los cuales son artefactos culturales construidos a través de generaciones para contener facilidades permanentes que incluyen campos, terrazas, canales, pantanos y reservorios para agricultura.

Según estos autores, la ingeniería de los paisajes es una variable cuantitativa que puede ser medida a través del tiempo por la cantidad de trabajo invertido en la construcción y la modificación de los paisajes. Así, al determinar los usos de la ingeniería de paisajes, los arqueólogos pueden interpretar cómo se alcanzaron los objetivos humanos al crear paisajes a través del tiempo. Otros ejemplos de paisajes con ingeniería también pueden ser los muros para fortificaciones, caminos, edificaciones administrativas, monumentos y plazas ceremoniales, aldeas y eventualmente ciudades.

El uso diferencial de las estrategias usadas por las élites para producir, transformar y distribuir excedentes agrícolas, y la diversidad en las formas de organización de la producción agrícola están relacionadas con la considerable variabilidad en la diferenciación en estatus, centralización política y patrones regionales de asentamiento observados en las sociedades cacicales alrededor del mundo. En general, aunque los arqueólogos se han preocupado por entender los sistemas agrícolas prehispánicos, el excesivo énfasis en aspectos descriptivos (aquellos argumentados desde la lógica histórico-cultural), ecológicos (en términos de la distribución de recursos a partir de variables medioambientales) o relacionados con la subsistencia (qué se consumía) y, en algunos casos, en relación con la producción intensiva de excedentes (lo cual se toma como un hecho que no requiere demostración ni evaluación), no ha permitido evaluar detalladamente las trayectorias de cambio agrícola y el modo como estas afectan el desarrollo de complejidad social. Asumir una perspectiva económica que se enfoque en la acumulación de capital landesque a través de la organización del trabajo y la ingeniería requerida para construir y transformar los paisajes de la producción agrícola es necesaria para entender las trayectorias de cambio social.

\section{Trayectorias de cambio agrícola: casos de estudio}

El énfasis en las trayectorias agrícolas y la organización del trabajo conduce a reflexionar como arqueólogos, por ejemplo, en temas como la escala de la producción; la forma como se tomaron decisiones en relación con los sistemas agrícolas (si necesariamente las élites intervinieron o las familias de cultivadores actuaron independientemente); la integración necesaria para la producción; la interacción entre los asentamientos y las zonas de cultivo con su 
efecto sobre los patrones de distribución de la población; la movilización de recursos y fuerza de trabajo; la intensificación agrícola con sus resultados en términos de las formas de producción, apropiación y circulación de excedentes; la transformación de excedentes agrícolas en riqueza, que se expresa en la producción, el intercambio y la acumulación de objetos suntuarios; la demografía y los ciclos de vida de las unidades domésticas involucradas en la construcción de paisajes agrícolas, entre otros problemas que podrían analizarse potencialmente a partir de una perspectiva económica de los paisajes.

A continuación, se presenta una discusión que parte del análisis comparativo de casos arqueológicos en los que la construcción de estructuras para la producción de excedentes alimentarios fue crítica para el surgimiento de desigualdad social. El principal criterio de selección de los casos fue la intervención antrópica a gran escala del paisaje y algunas otras características como la estructura organizacional de las sociedades analizadas y el tamaño demográfico, variables que han sido de especial interés para el autor por varios años.
Los casos que se presentan se encuentran localizados en el Valle Black Warrior (Estados Unidos), los Llanos de Moxos (Bolivia), la Isla de Marajo (Brasil), la región de Yaguachi (Ecuador), los Llanos de Barinas (Venezuela), los Llanos de Casanare y la región Calima (en Colombia) (Figura 1). Aunque en cada una de las regiones examinadas las comunidades recurrieron a la modificación del medio ambiente a través de la implementación de estructuras como campos elevados, montículos, estructuras hidráulicas, entre otras obras civiles, las causas, consecuencias $y$, en general, la secuencia en que ocurrieron las transformaciones sociales que acompañaron la creación de paisajes productivos fueron distintas en cada una de estas. El análisis de los casos presentados contradice la noción clásica de que solo existe una posible trayectoria de cambio agrícola (Boserup 1965) y, por el contrario, apoya la idea de que la variabilidad en la toma de decisiones en relación con la producción de alimentos pudo desembocar en distintas trayectorias tecnológicas y sociales (Morrison 1994). 
Figura 1. Casos de estudio referidos en el artículo.

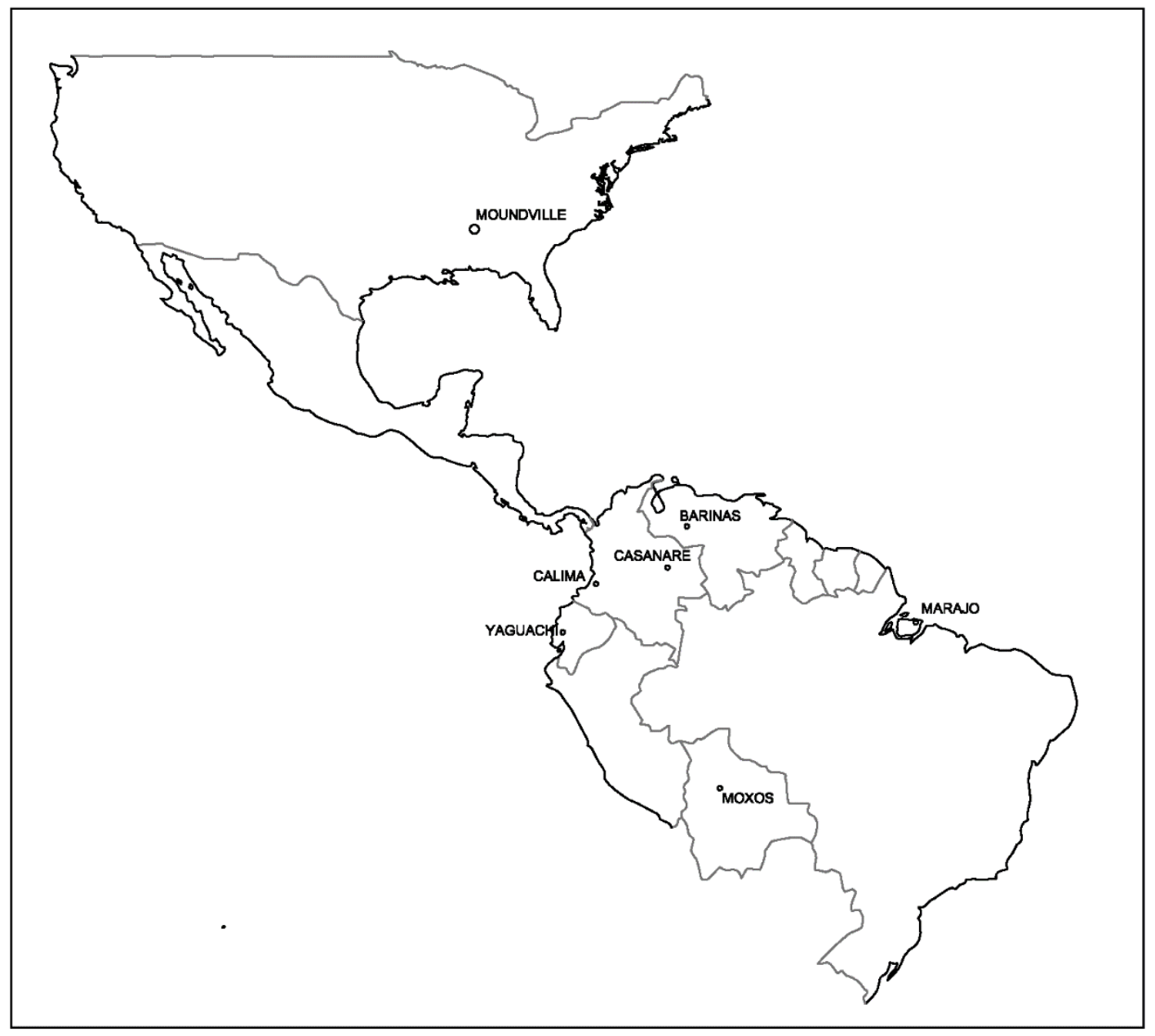

Fuente: Elaboración propia

\section{El Valle Black Warrior - Moundville}

Las sociedades complejas que habitaron en tiempos prehispánicos la región de Moundville entre 1000 y $1550 A$. $D$. han sido descritas por los arqueólogos como centralizadas o cacicazgos (Anderson, 1994; Blitz, 1999; Knight and Steponaitis, 1998; Steponaitis, 1978). Esta caracterización se basa principalmente en la supuesta presencia de una jerarquía de asentamientos, entre la que se distinguen tres niveles, encabezados por un centro regional donde se construyeron los más grandes montículos de la región, asentamientos de segundo nivel con pequeños montículos, y asentamientos de tercer nivel que se caracterizan por la presencia de un solo montículo (Blitz,
1999; Knight and Steponaitis, 1998; Welch, 1998). Al parecer, las elites de estas sociedades se dedicaron a la producción artesanal de bienes de prestigio, al intercambio a larga y mediana distancia, y a cumplir con funciones ceremoniales. Las sociedades Moundville se orientaron a la producción agrícola como principal actividad económica, la cual se intensifica hacia $1300 \mathrm{~A}$. D. De esta forma, la movilización de excedentes fue la clave para la consolidación del liderazgo a escala regional y local (Pebbles, 1987; Steponaitis, 1998; Welch, 1998). Según los modelos, la fundación de poblados monumentales fue el elemento clave que explicó las tendencias a la centralización demográfica observadas en la región. 
Se ha argumentado que la conformación de los patrones de asentamiento está relacionada con la interacción con las áreas de cultivo en una forma específica, y que la distancia entre los asentamientos está directamente vinculada al aprovisionamiento del trabajo agrícola (Stone, 1993). Este investigador también ha argumentado que la atracción generada por la intensificación en el uso de la tierra hacia las unidades domésticas es un principio básico de la organización espacial humana (Stone, 1993). Un fenómeno que puede observarse en Moundville es la conformación de agrupaciones alrededor de áreas agrícolas (Myer 2002).

En el caso de Moundville, Myer (2002) implementó un reconocimiento sistemático en dos sectores del Valle Black Warrior y encontró que la distribución de los caseríos agrícolas fue influenciada por la proximidad a los mayores cursos de agua, los aspectos geofluviales, la proximidad a montículos y a otros asentamientos rurales. Con base en el estudio de patrones de asentamiento, esta arqueóloga ha planteado que la continuidad en el uso de la tierra entre los períodos Woodland Tardío (500 - 1000 A. D.) y Mississippi (1000 - 1250 A. D.) sugiere que la localización de montículos individuales no influenció la localización de los asentamientos, sino viceversa (Myer 2002). En consecuencia, las tendencias a la agregación iniciales pudieron ser generadas por la disposición del trabajo agrícola en relación con la tierra disponible para cultivo. En este sentido, el surgimiento de una autoridad local, y posteriormente una regional, pudo ser una respuesta a la necesidad de controlar la población rural. Al localizar un centro monticular individual, la élite asociada o adyacente a una agrupación de sitios preexistentes pudo establecer su control a través del tiempo. Sin embargo, en lugar de crearse una agrupación de viviendas de cultivadores adyacentes en torno a un montículo, hubo inicialmente un grupo de asentamientos rurales que facilitaron la construcción de un montículo como residencia de la élite local, posterior a su fundación.
En el caso de Moundville, es probable que haya sido la gestión desde abajo hacia arriba de la producción agrícola y los excedentes derivados de esta lo que posibilitó la construcción de montículos ceremoniales para uso de la élite local emergente. Adicional a esto, Myers (2002) demuestra que la cantidad de asentamientos alrededor del centro regional de Moundville es baja, mientras que esta aumenta en zonas óptimas para cultivo, lo cual sugiere que, en este caso, la disposición de recursos y trabajo agrícola, mas no la localización de un centro ceremonial y político, resultó el elemento clave que afectó la distribución de la población. Es importante mencionar que en la región no hay evidencia de la construcción de facilidades agrícolas, lo que sugiere que no hubo acumulación de trabajo agrícola en forma de capital landesque, a pesar de que, al parecer, se hubiese implementado una forma de intensificación basada en la selección de algunas especies de plantas (Smith 1995).

Quizá como resultado de este proceso, las comunidades de Moundville crearon un paisaje ritualizado que sirvió a la élite para reclamar y establecer prerrogativas en el acceso a recursos agrícolas y fuerza de trabajo, así como para restringir la producción artesanal de bienes de prestigio que fueron básicos para el establecimiento de alianzas y el mantenimiento del poder político y religioso.

\section{Las sociedades de las tierras bajas de Suramérica y la producción agrícola}

En la arqueología de las tierras bajas de América del Sur, una de las cuestiones más importantes ha sido la aparición de la complejidad social y su relación con la intensificación de la producción de alimentos (Delgado, 2002; Denevan, 2001; Drennan, 1996; Roosevelt, 1994, 1999; Schaan, 2004, 2009). Las posiciones iniciales sugerían la imposibilidad de que este entorno tropical limitado y pobre pudiera soportar poblaciones grandes y sedentarias en tiempos prehispánicos (Meggers, 1992). Las posiciones más recientes han propuesto el surgimiento de sociedades 
complejas en tiempos preeuropeos que estuvieron organizadas en formas jerárquicas y/o heterárquicas, que se caracterizaron por su capacidad de transformar el medio ambiente y crear paisajes dedicados a producir excedentes de alimentos direccionados al financiamiento y mantenimiento de instituciones de poder (Roosevelt, 1999).

La imagen actual de las sociedades de las tierras bajas se ha construido sobre la base de algunas características comunes (Delgado, 2002; Denevan, 2001; Erickson, 2008; Heckenberger, 2005; Redmond et al., 1999; Roosevelt, 1999; Rostain, 2008; Schaan, 2004; Walker, 2004). Estas sociedades se establecieron en sitios con una plaza central y exhiben un mayor volumen de trabajo invertido en la acumulación de capital landesque a través de la construcción de arquitectura monumental y facilidades productivas, que fueron gradualmente dejando huellas complejas en el paisaje a través del tiempo y el espacio. Su monumentalidad y su tamaño representan las diferentes jerarquías administrativas que, a nivel regional, se expresan en la configuración de patrones de asentamiento jerárquicos compuestos por dos o tres niveles de toma de decisiones. Alguna diferenciación sociopolítica se expresa a través de la variación en la arquitectura de los hogares y/o entierros y artefactos asociados a ellos que podrían interpretarse como diferencias en estatus y acumulación de riqueza. La transformación del entorno natural en un paisaje de ingeniería por medio de zanjas, estanques, canales de riego y campos elevados para producir alimentos de manera intensiva es una característica típica de estas sociedades. Finalmente, estas sociedades construyeron calzadas y caminos, y utilizaron los ríos y arroyos para movilizar productos básicos, suntuarios y personas de una región a otra.

A pesar de esta caracterización amplia y general, las sociedades prehispánicas en las tierras bajas también exhibieron diferencias importantes relacionadas con la producción agrícola, que quizá podrían explicar la diversidad en las formas de organización y el grado de complejidad que exhiben entre ellas, al igual que las distintas escalas de intervención y modificación del paisaje que pudieron implementar, como se presenta a continuación.

\section{Los cacicazgos Yaguachi}

En la región de Yaguachi, Ecuador, hay una serie de sitios monumentales que surgieron durante el Período de Integración (750 - 1450 A. D.). En esta región, se ha identificado una jerarquía de asentamientos de tres niveles que se ha definido de acuerdo con la monumentalidad y el tamaño del sitio (Delgado, 2002). Los sitios más grandes se han considerado como los lugares centrales de una organización regional. Los sitios secundarios se caracterizan porque su monumentalidad y tamaño son más discretos, en comparación con los centros primarios regionales. El tercer nivel está compuesto por caseríos agrícolas y viviendas aisladas. La ubicación de los centros primarios regionales en las proximidades de los principales ríos sugiere que participaron en actividades de intercambio fluvial. Las proyecciones demográficas indican que durante el Período de Integración hubo entre 30.000 y 40.000 personas, sin embargo, no hay evidencia de presión demográfica sobre los recursos en esta región (Delgado, 2002).

En Yaguachi existe una clara correlación entre los centros regionales y los campos elevados, que sugiere una fuerte centralización y control directo por parte de las élites regionales sobre la producción de los campos, la organización del trabajo y la distribución de excedentes (Delgado, 2002). Este hecho ha sido interpretado como evidencia de competencia entre las élites locales, aunque en este caso se plantea que el elemento crítico de dicha competencia no fue el acceso a los recursos, sino la fuerza de trabajo disponible (Delgado 2002). Esta hipótesis se sustenta en la tendencia de las unidades domésticas agrícolas a agruparse alrededor de los principales centros regionales, que sugiere un esfuerzo por parte de las élites para concentrar trabajo alrededor suyo (Delgado, 2002). Las fechas disponibles indican que, en este caso, la construcción monticular precedió la construcción de campos elevados, lo 
que contrasta con la trayectoria agrícola propuesta para Moundville.

La investigación de Delgado (2002) en relación con la producción agrícola sugiere que el cultivo de los grandes campos elevados fue realizado por grupos de trabajo. Este argumento es respaldado por evidencia funeraria que indica una orientación hacia los entierros colectivos en áreas públicas y no en privadas. El entierro público y colectivo, opina Delgado (2002), fue un factor de cohesión para estas comunidades. El entierro primario de individuos, entremezclado con entierros secundarios depositados anteriormente, sugiere que esta actividad fue ejecutada comunalmente y no por las unidades domésticas (Delgado, 2002). Adicional a esto, fue posible observar un tratamiento diferencial en los enterramientos secundarios, lo que sugiere la existencia de una organización social diferenciada.

Delgado (2002) ha propuesto que la producción de campos elevados se basó en el trabajo de las comunidades locales que fueron coordinadas por sus jefes, quienes aprovecharon esta estructura laboral para promover sus propios intereses. De esta forma, la estrategia productiva se basaba en familias de cultivadores que proporcionaban excedentes de producción a los jefes locales mediante el manejo individual de parcelas en campos elevados (Delgado, 2002). Estos campos generaron altos rendimientos que pudieron alimentar poblaciones bastante grandes $y$ suficientes excedentes para ser invertidos por las élites locales en actividades de autoengrandecimiento, como la realización de fiestas y la construcción de monumentalidades (Delgado, 2002).

En resumen, el resultado en la región de Yaguachi del surgimiento de la complejidad social con base en el control centralizado de las actividades agrícolas $\mathrm{y}$, posiblemente, la transmisión de capital landesque, siguiendo a Tarwick (2008), fue la construcción de un territorio cultivado y monumentalizado que perteneció a estas comunidades. En otras palabras, la organización social característica de los cacicazgos Yaguachi permitió que el trabajo colectivo de familias agrícolas, quienes cooperaron con su propia dominación mediante su participación en actividades ceremoniales y transferencias de recursos agrícolas excedentes, quedara acumulado en el paisaje en forma monumental, lo que al parecer es un buen ejemplo de una estrategia de organización orientada desde arriba hacia abajo.

\section{Los Cacicazgos Cayuvava en los Llanos de Moxos}

Esta secuencia agrícola se refiere a las sociedades asentadas entre los ríos Iruyañez y Omi en los Llanos de Moxos en Bolivia. En la época prehispánica, una amplia área de esta región estuvo cubierta por campos elevados dedicados al drenaje de los suelos. La evidencia etnohistórica y arqueológica sugiere que, antes de la llegada de los españoles (siglo XV) a esta región, las sociedades asentadas allí estaban organizadas en "jefaturas" (Walker, 2004).

Aunque la información disponible sobre la organización social de estas comunidades es muy escasa, es posible reconstruir algunos aspectos relacionados con la organización del trabajo y la producción agrícola con base en el trabajo de Walker (2004). En esta región no hay evidencia de asentamientos monumentales como en la isla de Marajó y la región de Yaguachi. Tampoco existe información sobre patrones o actividades domésticas. Los asentamientos en esta región eran densos y Walker sugiere que, en el sitio del Cerro, durante el siglo XV, la población pudo oscilar entre las 2.000 y 5.000 personas, con sitios de tamaños entre 8,5 y 20 hectáreas. La población total en la región pudo alcanzar 10.000 personas (Walker, 2004).

De acuerdo con los relatos etnohistóricos, la producción agrícola de los campos elevados permitió la generación de excedentes que probablemente se invirtieron en festines y otros tipos de actividades suntuarias (Walker, 2004). 
Walker (2004) ha propuesto algunas características relacionadas con la organización del trabajo y la producción en los campos elevados. De acuerdo con los criterios espaciales, estas estructuras agrícolas se han clasificado en "campos elevados individuales" y "grupos de campos elevados" (Walker, 2004, p. 51). Los "campos individuales elevados" son campos aislados que probablemente fueron construidos por unidades familiares. La disposición de estos campos individuales sugiere que no hubo estructuras con las cuales los agricultores que viven aguas arriba pudieran controlar el suministro de agua de los agricultores aguas abajo. El sistema requería poca o ninguna gestión del agua y no existía una toma de decisiones comunitaria (Walker, 2004). Por otro lado, los "grupos de campo elevados" requirieron una gran inversión en mano de obra, lo que significa que muchas personas participaron en su construcción. Las proyecciones de trabajo y producción sugieren que estos sistemas se organizaron a nivel comunitario, aunque su construcción no requirió la coordinación de grandes grupos de personas (Walker, 2004). Walker sugiere que: "la agricultura de campos elevados no dependía de la concentración de la población en grandes aldeas, pero la concentración de la población en grandes aldeas pudo haber dependido de la agricultura intensiva" (Walker, 2004, p. 119).

En contraste con la región norte que ha analizado Walker (2004), en el sur y occidente de los Llanos de Moxos se han registrado estructuras monticulares asociadas a enterramientos, campos elevados y redes de caminos que conforman un paisaje complejo y "domesticado". Esta complejidad contrasta con la simplicidad de las estructuras agrícolas en las zonas norte y oriental de la región (Walker, 2008). La domesticación del paisaje, para Walker (2008), es un proceso que se da gradualmente y que guarda estrecha relación con el propósito de las poblaciones nativas de aumentar la agrodiversidad en la región. Erickson (2006) ha planteado que el proceso de domesticación de los paisajes ocurre cuando las comunidades humanas manipulan el fuego, el agua y los suelos para cambiar la distribución de plantas y animales. La diversidad observada en la región de Moxos, en términos de la construcción y la acumulación de capital landesque, para Walker, se relaciona con la magnitud de la fuerza de trabajo disponible, el tipo de problemas que confrontaron las comunidades en términos agroecológicos y el grado de organización social que pudieron articular. En este caso, también pudieron influir factores agroecológicos como la capacidad de absorción de agua o los contenidos de nutrientes en los suelos, entre otros (Walker, 2004).

En los Llanos de Moxos, la variabilidad de los campos y la monumentalidad cívico-ceremonial puede dar cuenta de distintas prácticas agrícolas que requirieron distintas formas de organización: algunas que involucraron pocas familias (modelo de abajo hacia arriba), otras el concurso de muchas y la coordinación por parte de unos pocos individuos (modelo arriba a abajo), siendo un buen ejemplo de la coexistencia de estos dos tipos de organización. De esta forma, las transformaciones ocurridas a gran escala en el paisaje, y que se observan en una gran inversión en acumulación de capital landesque, pudieron ser el resultado de cambios que se dieron a pequeña escala y que involucraron desde una familia, pocas familias, hasta comunidades enteras.

\section{Las sociedades Camutins de Marajoara}

Las principales figuras de la arqueología amazónica han estudiado las poblaciones prehispánicas de la isla de Marajó (Brasil) en relación con su capacidad para transformar el medioambiente por medio de la creación de monumentalidad cívico-ceremonial, ya que esta representa la evidencia de complejidad social en el área. La discusión gira en torno al papel que jugó la agricultura intensiva en el desarrollo de la complejidad social, haciendo énfasis en la calidad y la extensión de los suelos disponibles para cultivo. El modelo propuesto por Meggers (1992) supone que, dadas las limitaciones de los suelos en la isla, el desarrollo de agricultura intensiva fue imposible, por lo que las 
poblaciones locales se concentraron en la explotación de palma en un sistema donde el forrajeo de recursos salvajes permitió sostener poblaciones bastante densas. El modelo de Meggers ha sido criticado por otros investigadores, ya que no toma en cuenta la capacidad que tienen las poblaciones humanas para mejorar los suelos para cultivo por medio de prácticas culturales $\mathrm{y}$, en esta forma, modificar la capacidad de carga de sus hábitats, ni tampoco la diversidad en términos de disponibilidad de recursos que causa la distribución de los suelos en las zonas de várzea y de tierra firme (Carneiro, 1961, 1970; Gross, 1975; Lathrap, 1970; Roosevelt, 1980, 1989, 1999).

En contraste, según Roosevelt (1991), al ser Marajo una planicie inundable y estar localizada en las tierras de várzea, se caracteriza por su gran potencial para la producción intensiva de maíz. A pesar de esta expectativa, ella no ha encontrado durante sus investigaciones evidencia de cultivo intensivo de maíz, por el contrario, ha concluido que su consumo fue secundario para la dieta de estas comunidades y que quizá fue usado para producir bebidas fermentadas en la realización de fiestas. Estos resultados llevaron a la mismo Roosevelt a plantear que las limitaciones ecológicas para el desarrollo de la agricultura no fueron un impedimento para el surgimiento de complejidad social, sino al contrario, estas imponían la necesidad de implementar distintos sistemas de subsistencia, los cuales se relacionaban con distintas formas de organización social. Para Rossevelt (1999), ante la imposibilidad de producir excedentes agrícolas, las poblaciones de Marajo se organizaron en formas heterárquicas.

Un tercer modelo ha sido propuesto por Schaan (2004) en el cual se plantea que, ante la imposibilidad de practicar agricultura intensiva para producir excedentes para el financiamiento de las instituciones de la economía política, las poblaciones de la isla implementaron sistemas de recursos acuáticos, que les permitieron generar los excedentes requeridos para el desarrollo de sistemas sociales jerarquizados. Desde su perspectiva, la producción y acumulación de excedentes pesqueros y no agrícolas guardó relación con la creación de un paisaje monumental y productivo.

Durante la fase Marajoara (400 - 1300 d. C.), las poblaciones de la isla se asentaron a lo largo del curso de las arterias fluviales, en poblados nucleados en los cuales construyeron arquitectura monticular de gran escala. Las investigaciones han sugerido que el uso de estas construcciones fue posiblemente residencial y ceremonial, ya que pudieron servir como escenario para la conmemoración de fiestas encabezadas por las familias de las élites locales (Schaan, 2004).

El aumento de los sitios durante este período, en comparación con la fase previa, indica crecimiento de la población (Schaan, 2004), la cual pudo estar alrededor de 2.000 personas. En el año $700 \mathrm{AD}$, las poblaciones asentadas a lo largo del río Camutins emprendieron la modificación del paisaje mediante la movilización de grandes volúmenes de tierra, con el fin de crear complejos sistemas de control del agua, compuestos por pantanos, estanques y montículos. Schaan (2004) ha propuesto que estos sistemas representan facilidades tecnológicas antiguas dirigidas a intensificar la explotación de los recursos acuáticos para pesca, los cuales representarían una forma alterna de capital landesque, si se considera en términos de la acumulación de recursos y trabajo, y la posibilidad de ser heredados de forma transgeneracional.

La ocupación permanente de los montículos sugiere que la vida sedentaria fue un requisito para la implementación de los sistemas de gestión del agua porque su mantenimiento requería formas de cooperación y administración estables. La implementación de estas construcciones requirió una inversión comunal de mano de obra, que fue crítica para el desarrollo de un sentido de territorialidad y para 
el surgimiento de relaciones sociales y económicas jerárquicas. Schaan (2004) ha sugerido que el sistema basado en la pesca permitió la producción de una cantidad adecuada de excedente con una inversión mínima de trabajo, que pudo ser movilizado por las élites locales y regionales.

Aunque el mantenimiento del sistema era esencial, la conformación de grupos de trabajo colectivo pudo ser una solución adecuada para reducir la cantidad de inversión de energía por unidad laboral mientras se intensificaba la producción. En este tipo de estrategia de producción intensiva de alimentos, los rendimientos excedentes pueden ser bastante altos, aunque requiere de igual manera inversiones elevadas de trabajo, por lo que la cooperación es la mejor manera de maximizar la producción mientras se minimizan los costos de producción (Schaan, 2004). Schaan (2004) ha planteado que estos sistemas pesqueros estuvieron controlados por aquellas familias que arribaron primero a la isla, es decir que la autoridad y el prestigio se basó en principios de "ancestría". A pesar de que en el registro arqueológico se observan diferencias entre los ajuares asociados a las viviendas de aquellos que han sido considerados como élites, estas no son tan marcadas con las viviendas de los segmentos comuneros, lo que sugiere que la acumulación conspicua de riqueza no fue una de las características con las que se ejerció el poder en estas comunidades (Schaan, 2004).

Detrás del modelo propuesto por Schaan, está la idea de que la restricción ambiental es una condición previa para el surgimiento de la complejidad social, porque brinda oportunidades a los "patrocinadores" (patrons) para tomar ventaja económica sobre sus "clientes" (Smith y Choi, 2007; Lepofski et al., 2005). Otro elemento crítico en este modelo es la producción de excedentes y su intercambio, ya que ambas actividades permiten la consolidación del poder de las élites emergentes. Para tener éxito, los líderes deben consolidar su autoridad a través de la expansión de las relaciones internas y externas, y mediante el establecimiento de alianzas basadas en el intercambio de bienes y productos (Spencer, 1993, 1994). Según Schaan, los cacicazgos de Marajoara se basaban en una economía de "productos básicos" que se utilizaba para comerciar con otros alimentos y bienes (Schaan, 2004, p. 388).

La necesidad de aumentar la producción de excedentes supone que las personas deben trabajar en una organización laboral más eficiente, para que puedan surgir trabajadores especializados en ciertos oficios críticos para el mantenimiento y reproducción del sistema. Stanish (2004) ha sugerido que, para lograr este objetivo, se deben cumplir dos condiciones: 1) los beneficios de la cooperación deben superar los beneficios obtenidos y los costos que pueden ser obtenidos o asumidos por los individuos; 2) debe existir un mecanismo social que pueda mantener la organización laboral: este mecanismo es la ideología. En relación con la primera condición, Schaan (2004) sugirió que, de acuerdo con la ausencia de coerción social en el registro arqueológico, debería existir una relación de obligaciones mutuas entre los seguidores y sus líderes. De esta forma, los comuneros pudieron contribuir con su trabajo y posiblemente con otros productos sobre los cuales la élite no tenía control directo, lo que sugiere la posible coexistencia de organización orientada desde abajo hacia arriba y viceversa. La élite, en reciprocidad, pudo pagar con protección y recursos alimenticios en un contexto ideológico en el que la relación con los dioses y antepasados era central (Schaan, 2004).

En relación con la segunda condición, Schaan ha considerado que, en las sociedades de Camutins, los festines pudieron ser un escenario colectivo en el que se expresó la competencia ideológica por los recursos básicos y el poder político (Schaan, 2004). Las estrategias productivas y la escala de la organización laboral implementada por los cacicazgos Camutins se manifiesta en el paisaje, en un conjunto de obras monumentales y facilidades productivas que quedaron acumuladas en él en forma de capital landesque y que, en este caso, según Schaan, fueron clave 
para el surgimiento de jerarquías regionales y locales.

\section{Las estrategias agrícolas en los Llanos del Orinoco}

En los Llanos de la cuenca del Orinoco, la evidencia arqueológica indica que la intensificación agrícola fue en gran medida un proyecto emprendido por las élites (Whitehead, 1994). Para los Llanos de Barinas, Venezuela, se han presentado dos argumentos principales para explicar la intensificación agrícola prehispánica que se manifiesta en el paisaje llanero en forma de grandes áreas cubiertas de campos elevados. Por una parte, se ha argumentado que fue una respuesta a la presión demográfica en una región de potencial productivo limitado (Zucchi y Denevan, 1979) o, alternativamente, que fue una estrategia para lidiar con el riesgo ambiental para la producción agrícola (Gassón, 1998; Spencer 1998). El argumento que sugiere presión poblacional es débil porque, aunque hubo un aumento en la población entre 1 y 500 AD, cuando se construyeron los sistemas de campo elevados, aún había grandes áreas aptas para el cultivo en los Llanos de Barinas que permanecieron vacías. Además, los estudios arqueológicos en las regiones de El Gaván y El Cedral indican que, aunque entre el 1 y 1000 AD la población regional creció, se mantuvo muy por debajo del nivel que generaría presión sobre los recursos (Gassón, 1998; Spencer et al., 1994).

Por el contrario, la disponibilidad de agua en los Llanos resulta frecuentemente impredecible, ya que se relaciona con la existencia de ciclos a corto plazo (un año), mediano plazo (entre 3 y 5 años) y largo plazo (más de 10 años), relacionados con fluctuaciones climáticas que resultan en sequías prolongadas e inundaciones destructivas, lo cual representa riesgos para la producción agrícola basada en tala y quema, pequeños jardines y huertas en los Llanos (Gassón, 1998). La intensificación agrícola basada en la construcción de sistemas de campos elevados pudo ayudar a amortiguar el riesgo ambiental (Gassón, 1998; Spencer, 1993, 1994). En consecuencia, los recursos agrícolas generados en los campos elevados podrían haberse usado durante los años malos en los que las prácticas agrícolas alternativas no pudieron abastecer completamente a las poblaciones locales. Durante los años buenos, en los cuales el cultivo de pequeños huertos y jardines tuvo éxito, la producción en campos elevados generó excedentes que podrían haber sido dirigidos hacia actividades políticas de élite tales como guerra, fiestas, intercambio de larga distancia y construcción de arquitectura monumental, que pudieron incrementar el estatus, la riqueza, el poder o la autoridad de las élites (Gassón, 1998; Spencer, 1993, 1994).

La evidencia arqueológica recuperada durante el reconocimiento regional llevado por Vargas (2017) en la región de Catanga sugiere que las entidades políticas de Casanare eran más pequeñas en escala espacial y demográfica que en Barinas. La información sobre las unidades políticas de Barinas del período Gaván Tardío (550 - $1000 \mathrm{AD})$ indican que una distancia radial de $12,5 \mathrm{~km}\left(490 \mathrm{~km}^{2}\right)$ es una buena medida de la extensión territorial de las entidades políticas en los Llanos. En algunos casos, como en la unidad política de El Cedral, el tamaño territorial pudo alcanzar los $600 \mathrm{~km}^{2}$. En Casanare, las comunidades supralocales de los períodos Catanga Temprano, Medio y Tardío no superan los $200 \mathrm{~km}^{2}$. Las diferencias en la extensión del territorio principal y en el tamaño de los centros regionales pueden ser la expresión de las diferentes trayectorias demográficas en cada unidad política. En el caso de Barinas, durante los últimos años de ocupación del período Gaván Tardío, alrededor de $4.000-6.000$ personas componían la población regional de la jefatura de El Cedral, mientras que aproximadamente 2.000 - 3.000 personas integraban la comunidad supralocal del Gaván (Vargas, 2011, 2012). Por otro lado, la población de toda la región de Catanga no superó las 1.000 personas durante el Período Catanga Tardío, el momento en que esta política experimentó su máximo demográfico. 
El registro arqueológico de Catanga sugiere que la escala de producción y el tamaño de la población de estas comunidades era pequeña en comparación con la de Barinas. Estas diferencias implican diferentes tipos de problemas que cada unidad política tenía para la coordinación de las actividades agrícolas. Como se ha planteado, las diferencias demográficas entre estas tres unidades políticas fueron bastante pronunciadas. Cuando se compara la extensión de los campos elevados entre estas tres entidades territoriales, hay una gran diferencia entre ellas: en la región de El Gaván, alrededor de 900 hectáreas fueron cubiertas por campos elevados; en El Cedral, 2.100 hectáreas; y en Catanga, alrededor de 500 hectáreas. Sucede lo mismo al comparar la distribución de los campos elevados en relación con los centros primarios regionales. En el Cedral, los campos de cultivo están directamente asociados al centro primario; en el Gaván fueron ubicados en la periferia de asentamientos de menor tamaño, pero con monumentalidad, los cuales estuvieron unidos por una red de caminos al centro regional; mientras en Catanga, los campos estuvieron dispersos en áreas entre las comunidades (Gassón y Rey, 2006; Vargas 2012, 2017). Es muy probable que las diferencias en la demografía hayan generado variabilidad en la capacidad de estas sociedades para modificar su paisaje mediante la implementación de campos elevados, producir y movilizar excedentes, y desarrollar una economía a gran escala.

Para analizar cómo se organizó el régimen agrícola de cada una de estas sociedades, es útil estudiar las diferentes alternativas que siguieron estas comunidades. Es probable que, bajo un régimen de producción de roza y quema, los pobladores antiguos de Catanga pudieron experimentar algunas limitaciones relacionadas con la fuerza de trabajo disponible para aumentar la producción de excedentes agrícolas y construir un paisaje de producción a gran escala, similar al de Barinas. De hecho, Whitehead (1994), Drennan (1996) y Gassón (1998) coinciden en que el elemento crítico en los Llanos para la agricultura fue la mano de obra y no la tierra. Bajo estas circunstancias, el espectro de estrategias políticas que los gobernantes emergentes de las comunidades locales de Catanga podrían haber desarrollado, se limitó a aquellas tales como las fiestas y el intercambio externo que no requirieron la inversión de grandes cantidades de excedentes, como sí fue necesario para la arquitectura monumental implementada por las unidades políticas de Barinas, y que resultó en intervenciones de gran magnitud de los ecosistemas y en la creación de megapaisajes de la producción.

En los Llanos existe una relación directa entre la cantidad de mano de obra disponible para la agricultura, la magnitud de las áreas de cultivo, la magnitud de los excedentes disponibles y la magnitud de las modificaciones del paisaje implementadas en cada región. Netting (1974) ha argumentado que la cuestión relevante en este asunto se refiere a las condiciones bajo las cuales se produce la intensificación agrícola y las técnicas y costos necesarios para alcanzar varios niveles de rendimiento. El registro arqueológico sugiere que los líderes de Barinas tuvieron acceso a rendimientos más altos que los de Casanare. La diferencia en la capacidad de producir excedentes agrícolas no es solo el resultado de los diferentes tamaños de población en cada región (o la fuerza de trabajo disponible), también es una consecuencia de las diferentes estrategias de organización laboral que implementó cada unidad política.

La fuerza y la organización del trabajo se ven afectadas por los entornos demográficos específicos de las comunidades locales y la comunidad política. Mientras Johnson (1982) ha propuesto que el tamaño de la unidad de residencia está relacionado con los requerimientos laborales y la tenencia de la tierra, Stone (1996) ha señalado que la agricultura involucra cuestiones sociales como el tamaño de los grupos de trabajo, la duración del trabajo y la capacidad de las comunidades para cumplir con las demandas laborales.

Gassón y Rey (2006) han argumentado que las diferencias en la distribución de campos 
elevados entre El Gaván y El Cedral expresan diferentes estrategias de movilización de excedentes y control sociopolítico. Es probable que las estructuras organizativas de las políticas de El Gaván y El Cedral fueran más jerárquicas y complejas que las de la unidad política de Catanga. Si es así, es posible que una población más grande y una organización más jerárquica hayan brindado oportunidades a las élites en Barinas para movilizar y apropiarse de mayores excedentes, y financiar sus actividades políticas e ideológicas, como la modificación del paisaje a través de arquitectura monumental (Spencer, 1994). Por otro lado, en un contexto regional como el de Catanga, en el que el tamaño de la población era reducido, existe la posibilidad que hubiera surgido una organización menos jerárquica. Así, las características demográficas y organizativas laborales de las unidades políticas llaneras probablemente limitaron la cantidad de excedentes que los gobernantes emergentes pudieron acumular para promover estrategias como la construcción de obras monumentales cívico-ceremoniales. Sin embargo, en ambos casos se construyeron estructuras agrícolas que son evidencia de la capacidad de estas comunidades de acumular trabajo en el paisaje con fines productivos (capital landesque).

En los Llanos del Orinoco, el crecimiento poblacional moderado, las diversas formas de organización sociopolítica de las comunidades supralocales, el requerimiento por generar excedentes orientados a consumo social, junto con la manipulación medioambiental interactuaron para crear paisajes de ingeniería agrícola de diversas escalas y capacidades productivas, lo que se expresa en una capacidad diferencial para acumular capital landesque, y en la variabilidad en las respectivas trayectorias de cambio a pesar de compartir algunos patrones de comportamiento y uso del espacio.

\section{La región Calima}

Las investigaciones arqueológicas realizadas en la región Calima sugieren que, desde el período
Yotoco hasta el Sonso (alrededor de $500 \mathrm{AD}$ a $1300 \mathrm{AD}$, aunque no hay consenso en la cronología entre investigadores), el medioambiente en la región fue modificado a gran escala como consecuencia del aumento en la producción agrícola. Se ha propuesto que durante estos períodos las poblaciones nativas posiblemente hayan implementado estrategias intensivas de cultivo que resultaron en la creación de paisajes agrícolas (Bray, 2005; Salas, 2017). Una de las explicaciones que se ha dado es el crecimiento poblacional, sin embargo, al considerar otras trayectorias de cambio social en el mundo, junto con las otras líneas de evidencia presentes en la región, una hipótesis alternativa que podría explicar la implementación de estrategias de cultivo intensivas en la región Calima puede estar relacionada con la necesidad de producir excedentes para invertir en consumo social y el financiamiento de redes de prestigio. Salas (2017) propone para el Valle del Dorado que la agricultura intensiva no se relacionó con crecimiento poblacional o con la necesidad de producción de excedentes, y plantea que esta pudo estar relacionada con la ideología de las comunidades y la continuidad de prácticas ancestrales, y no exclusivamente con la economía. En este sentido, Hayden (1995) propone que el ceremonialismo, las fiestas y otras actividades de tipo ritual y carácter público requieren la inversión de excedentes alimenticios para su realización. De ser así, la creación del paisaje agrícola en este caso pudo estar orientada por la producción intensiva a promocionar la competencia social entre líderes emergentes (Gassón, 1998).

En la región Calima, las comunidades posiblemente tuvieron que confrontar problemas relacionados con las condiciones pedológicas, especialmente con el drenaje de los suelos posiblemente afectados por las altas concentraciones de cenizas volcánicas, que llevaron a las poblaciones Yotoco y Sonso a construir facilidades agrícolas como campos elevados y sistemas de drenaje basados en zanjas (Bray et al., 1987). Al parecer, la técnica de roza 
y quema implementada por los habitantes prehispánicos pudo someter los suelos a procesos erosivos, por lo que se ha propuesto que algunas estructuras agrícolas fueron implementadas para lidiar con este problema (Bray, 2005). En el caso del Valle del Dorado, Salas (2017) también identifica que las zonas donde se implementaron facilidades agrícolas y obras hidráulicas son aquellas con suelos deficientes para el cultivo. También se ha sugerido que es posible que algunas de estas zanjas hayan servido para delimitar lotes de cultivo asociados directamente a unidades domésticas, lo que indicaría la aparición de apropiación de tierras por algunas familias de la región (Bray, 2005).

La sobreposición en algunas zonas de áreas de habitación correspondientes al período Sonso y la construcción de nuevas facilidades agrícolas sobre algunas zanjas y canales que pudieron ser usados para cultivo durante el período Yotoco, sugieren una reorganización del espacio y una expansión de la frontera agrícola entre estos dos períodos. También se ha argumentado que es posible que hacia $1200 \mathrm{AD}$ el clima fuera más seco a causa de una variación continental que pudo tener como efecto el abandono de los campos elevados construidos en las zonas bajas del valle y una reorientación de las familias hacia la adecuación y sus pendientes estructurales con fines agrícolas (Bray et al., 1987).

La gran capacidad de modificación del paisaje de las poblaciones Yotoco y Sonso, también se puede observar en la construcción de amplias redes de caminos y de aterrazamientos de distintos tamaños o tambos que fueron usados como áreas de habitación (Bray, 2005; Salas, 2017). Es probable que estos tambos hayan sido ocupados por pocas personas, no sobrepasando unas pocas familias. La localización de los tambos indica una distribución dispersa de la población y probablemente el hecho de que el trabajo agrícola dependió de la organización a escala familiar. Estos patrones han sido observados también en el Alto Magdalena, donde Sánchez $(2005,2007)$ ha reportado estructuras agrícolas similares a las de la región
Calima. Para Sánchez (2007), en Isnos es posible que la construcción de facilidades agrícolas haya requerido la intervención de varias familias, las cuales transfirieron por diversos mecanismos explotativos, entre ellos los ideológicos, los excedentes derivados a las élites cacicales, invertidos para la promoción de sus intereses y el mantenimiento de sus posiciones políticas. Esta similitud en el manejo del paisaje, la distribución de la población y la posible organización parental del trabajo agrícola también ha sido identificada por Salas (2017) en el Valle del Dorado.

Es muy posible que también hayan existido pequeños y grandes poblados agrícolas que pudieron alcanzar varias hectáreas. Bray (2005) señala que desafortunadamente los sitios más grandes que han sido reportados carecen de información recolectada en forma sistemática, por lo que es imposible poder hacer proyecciones demográficas para este tipo de asentamientos. Sin embargo, es muy probable que estos asentamientos nucleados hayan agrupado a varias decenas de familias que, desde una perspectiva productiva, pudieron constituir una importante fuerza de trabajo que se pudo dedicar a la construcción de facilidades agrícolas y civiles. Aunque Bray (2005) señala que dada la falta de información es imposible hablar sobre las causas de la intensificación de la agricultura y el papel de los excedentes agrícolas en la economía política de estas sociedades, las evidencias actuales relacionadas con la agricultura, la alfarería, la metalurgia y la construcción de obras civiles, sugieren que los sistemas de cultivo prehispánicos fueron suficientemente productivos como para financiar actividades especializadas y destinar parte de la población a la construcción y el mantenimiento de facilidades agrícolas, habitacionales y de transporte.

En el caso de la región Calima, como afirman Bray et al. (1987), el paisaje no fue estático en el pasado, así como no lo es en el presente. Es evidente que, en este caso, la inversión de trabajo transformó la imagen de la región y su productividad a través de la construcción de 
paisajes, en el sentido económico que Earle y Doyer (2008) discuten al hablar de sistemas agrícolas de gran escala. Es pertinente preguntarse si la construcción y el mantenimiento de las estructuras agrícolas fueron emprendidos por los antiguos líderes de estas comunidades, quienes establecieron su control sobre la producción y centralizaron la movilización de excedentes, o si, por el contrario, la gestión del paisaje fue un asunto que emprendieron las familias de cultivadores autónomamente.

Sería muy interesante que, en futuras investigaciones en esta región, los arqueólogos se concentraran en estudiar las particularidades de los paisajes agrícolas que se han identificado en las importantes investigaciones que sentaron las bases de la arqueología Calima desde hace varias décadas. En este sentido, el trabajo de Salas (2017) constituye una gran contribución al análisis de problemas en torno a la agricultura, que no han sido resueltos desde un enfoque del paisaje. En el caso de la región Calima, y desde una perspectiva económica, la riqueza no solo puede interpretarse desde la parafernalia ritual o los bienes de prestigio, y la acumulación de trabajo en forma de capital landesque, pues también pudo ser una base sobre la cual algunas familias construyeron su base de poder en el pasado.

\section{Discusión}

En las distintas secuencias analizadas, aparentemente existe una relación directa entre la cantidad de mano de obra disponible para la agricultura (o pesca en el caso de Marajo), la magnitud de las áreas de cultivo, la magnitud de los excedentes disponibles y la escala de las modificaciones del paisaje implementadas en cada región. Netting (1974) ha argumentado que la cuestión relevante en este asunto se refiere a las condiciones bajo las cuales se produce la intensificación agrícola y las técnicas y los costos necesarios para alcanzar varios niveles de rendimiento. El registro arqueológico de los sitios aquí presentados sugiere que los líderes en las distintas regiones tuvieron acceso a diferentes cantidades de excedentes. La diferencia en la capacidad de producir excedentes agrícolas no es solo el resultado de los diferentes tamaños de población en cada región (o la fuerza de trabajo disponible), también es una consecuencia de las diferentes estrategias de organización laboral que implementó cada unidad política.

La fuerza y la organización del trabajo se ven afectadas por los entornos demográficos específicos de las comunidades locales y la comunidad política. Mientras Johnson (1982) ha propuesto que el tamaño de la unidad de residencia está relacionado con los requerimientos laborales y la tenencia de la tierra, Stone (1996) ha señalado que la agricultura involucra cuestiones sociales como el tamaño de los grupos de trabajo, la duración del trabajo y la capacidad de las comunidades para cumplir con las demandas laborales.

En términos demográficos, quizá la unidad política más grande fue la de Yaguachi, seguida de las de Barinas, Camutins, Cayuvava y Casanare. No se cuenta con proyecciones regionales para Moundville, ni para Calima. En términos de monumentalidad cívico-ceremonial, las sociedades que se distinguen por sus obras son Moundville, Cayuvava, Barinas y Camutins, mientras en las restantes hay ausencia de este tipo de estructuras, aunque existen modificaciones de paisaje de gran escala en el caso de Calima y de menor tamaño en Casanare.

Se elaboraron campos elevados para agricultura en Yaguachi, Cayuvava, Barinas, Casanare y Calima; sin embargo, no es posible establecer una comparación en términos de su escala, ya que no hay datos consolidados sobre la extensión de cada una de las regiones. En el caso de Moundville, aunque se habla de intensificación agrícola, no hay estructuras agrícolas similares que apoyen este argumento. Al parecer, el proceso de intensificación en el Valle Black Warrior se dio a través de la manipulación genética de diversas especies de plantas, lo que 
permitió a las comunidades obtener más cosechas por año (Smith, 1995).

Resultado de esta comparación, también es posible observar cómo las comunidades de la unidad política de Moundville crearon monumentalidad cívico-ceremonial en torno a áreas agrícolas, y las de Camutins lo hicieron en relación con las zonas de pesca, fenómeno posterior al establecimiento de asentamientos familiares de pequeño tamaño. En contraste, en Yaguachi y Barinas, la construcción de monumentalidad generó tendencias a la agregación de población y a la localización de los campos de cultivo en relación con los centros primarios y secundarios. Este es un resultado del esfuerzo que hacen las élites por atraer y controlar a sus seguidores a través del ceremonialismo y la santificación de su estatus, expresado en la construcción de monumentalidad. La construcción de paisajes ceremoniales y de producción en estos casos resulta ser evidencia de la relación dialéctica que se establece entre economía e ideología en las sociedades complejas.

En cuanto a la organización del trabajo en las trayectorias presentadas, también se revelan distintos patrones que van desde la coordinación de grupos reducidos de familias hasta la participación de comunidades enteras. La escala de intervención del paisaje, el análisis de la correlación entre áreas habitacionales y la distribución de facilidades agrícolas, como propone Walker (2004), Salas (2017) o Stone (1993), es fundamental para entender la diversidad de estrategias agrícolas que incluso pueden existir en una misma región. En Barinas o Yaguachi, aunque el trabajo estuvo organizado al nivel de la unidad doméstica, los campos fueron controlados directamente por las élites regionales o locales, quienes se apropiaron de las facilidades agrícolas y quizá las heredaron intergeneracionalmente, como forma de capital landesque. En Moundville, Casanare, Yaguvava y Camutins es posible que la producción y la acumulación de capital landesque se haya basado en la autogestión del paisaje por parte de las unidades domésticas, teniendo prelación ancestral aquellas que poblaron tempranamente cada una de las respectivas regiones.

Otro rasgo que surge al comparar las distintas trayectorias tiene que ver con el papel que desempeñó la agricultura para el surgimiento de complejidad social. Las sociedades Camutins son un buen ejemplo de cómo, a pesar de que se practica agricultura, las condiciones del medio ambiente fueron aprovechadas para intensificar la pesca, de forma tal que la escala de cultivo para estas sociedades se orientó más hacia la subsistencia y el ceremonialismo. Lo anterior contrasta con lo que conocemos de las sociedades de los Llanos del Orinoco, para las cuales la agricultura intensiva fue básica para la subsistencia y la producción de excedentes dirigidos a financiar su economía política, aunque la pesca también estuvo presente (Morey, 1975). No es difícil imaginar sociedades donde la agricultura y la pesca pudieron ser actividades de una escala similar, que aportaron excedentes en forma complementaria para el financiamiento de las instituciones sociopolíticas o religiosas; sin embargo, esta es una pregunta que requiere resolverse con información arqueológica.

Un elemento que ha pasado desapercibido en la discusión sobre los orígenes de la desigualdad tiene que ver con el hecho de que los modelos tradicionales plantean que las élites o los engrandecedores se apropian de los excedentes derivados de la producción agrícola de los cultivadores, directamente mediante la explotación. Para hacer esto, las élites usan su poder coercitivo o mecanismos ideológicos expresados en estatus de guerra, ceremonialismo o santificación del poder, expresados, por ejemplo, en la ritualización del paisaje a través de la monumentalidad. En el modelo clásico (top-down), las élites no producen excedentes alimentarios directamente, ya que se encuentran separadas de la producción; la relación que establecen con sus seguidores es básicamente explotativa (Saitta, 1994). La modificación del paisaje, en consecuencia, es el resultado de la gestión de los intereses de este segmento de la 
sociedad, mientras que el resto de la población solo aporta su trabajo a este propósito.

Por otra parte, también es posible que la producción y la apropiación alimentaria ocurra en el ámbito de la unidad doméstica. En este modelo, las familias de élite están involucradas directamente en la producción de alimentos y no establecen relaciones explotativas con el resto de las personas que componen su comunidad, lo que no quiere decir que no aspiren a la dominación política. Saitta (1994) ha propuesto que, en tales contextos, los líderes actúan como apropiadores comunales de excedentes, y el flujo de estos entre las élites y los productores es una transferencia comunalmente dirigida, la cual es garantizada por los productores a las élites como una compensación por su papel en la adquisición de bienes de prestigio y servicios (Saitta, 1994).

Para dilucidar en el registro arqueológico por cuál de estas alternativas se pudo haber optado en el pasado, se requiere, en consecuencia, evaluar la magnitud de las facilidades agrícolas o, en otras palabras, la escala del capital landesque que ha producido y acumulado una sociedad, la capacidad de transformar el paisaje a través de su ingeniería, que se refleja en la magnitud de la infraestructura agrícola y su complejidad, la ausencia/presencia de obras monumentales de carácter cívico-religioso, la escala de la producción excedentaria, la relación entre áreas de habitación y facilidades agrícolas y cómo esta se transforma o no a través del tiempo, y, por último, pero fundamental, la escala demográfica local y regional que, como se ha planteado, guarda estrecha relación con las formas de organización del trabajo que una comunidad o unidad política puede implementar.

\section{Conclusiones}

Este artículo presentó un conjunto de trayectorias arqueológicas en las cuales las poblaciones prehispánicas de distintas partes de Norte y Sur América modificaron el paisaje a partir de la implementación de distintas estrategias agrícolas y de pesca. La organización del trabajo, las condiciones medioambientales, el contexto demográfico, la capacidad de movilización de trabajo, la escala de la producción, la centralización demográfica y la ritualidad fueron variables que afectaron la escala y las formas como dichas poblaciones impactaron el paisaje. La historia de las economías humanas sugiere que la producción intensiva de alimentos tomó distintas formas y se organizó de manera variable, y que en muchos casos esta coincidió con el aumento de las densidades poblacionales, pero también con los requerimientos de financiación de instituciones sociopolíticas e ideológicas de unidades sociales cada vez más complejas (Earle y Doyel, 2008). En todos los casos analizados se pudo observar que los paisajes de la producción constituyeron recursos estratégicos, ya que representaron formas materializadas de acumulación excedentaria o capitales landesque para las comunidades, las familias que las integraron y las personas que las lideraron. En consecuencia, las diferencias en la magnitud de la ingeniería aplicada a los distintos paisajes entre las regiones analizadas podrían representar la variabilidad de las condiciones y las decisiones económicas que se tomaron en las distintas regiones. A pesar de esto, es importante reconocer que factores idiosincráticos como la santificación del poder, la ancestralidad, la identidad, también fueron centrales en este proceso.

Fisher y Feinman (2005) han hecho énfasis en la importancia de asumir desde la arqueología una perspectiva en la que la relación entre medioambiente y cambio cultural sea continuamente renegociada en una variedad de escalas temporales y espaciales, como resultado de la modificación por los grupos humanos que buscan satisfacer sus intereses sociales, políticos y económicos. En otras palabras, prácticas económicas como las formas de propiedad, el acceso a la tierra, la organización del trabajo, el intercambio y otros recursos no pueden estar divorciados analíticamente de los contextos sociales, el medioambiente físico y la transformación de los paisajes. Es de esta forma 
que podemos entender cómo el surgimiento de sociedades estratificadas y cambios en la demografía de las unidades domésticas crean un paisaje apropiado a través del tiempo. En este sentido, la producción de paisajes en la producción agrícola resulta uno de los mecanismos críticos de la economía política, es decir, de aquella que se dirige al financiamiento de las instituciones sociales.

Aunado a lo anterior, es necesario entender la intensificación agrícola como un proceso compuesto por múltiples estrategias y etapas, y no como un solo evento. En consecuencia, es importante comprender que en el pasado hubo múltiples trayectorias de cambio agrícola, más que una ruta simple que todas las sociedades siguieron (Morrison, 1994). La investigación arqueológica de la producción alimentaria debería tener en cuenta la posibilidad de que distintas trayectorias hayan podido estar presentes en una misma región simultánea o secuencialmente, y si fue así, qué representan o implican estas estrategias en términos de los distintos impactos que pudieron tener sobre la organización social de las sociedades del pasado. Desde esta perspectiva, se puede considerar que los modelos explicativos que consideran una sola trayectoria tecnológica en cuanto a la producción de alimentos ocultan o desconocen la variabilidad de las condiciones y opciones que las personas tuvieron a su disposición en el pasado. Asumir una perspectiva teórica y metodológica en la cual se considere la diversidad en el comportamiento humano, brinda la oportunidad de estudiar en forma comparativa los procesos, las variables y causas de la implementación de la agricultura y su relación con el surgimiento de la desigualdad y la complejidad social.

\section{Referencias bibliográficas}

Anderson, D. (1994). The Savannah River Chiefdoms: Political Change in the Late prehistoric Southeast. The University of Alabama Press. Tuscaloosa.
Blitz, JH. (2009). Mississippian Chiefdoms and the Fission-Fusion Process. American Antiquity 64, 577 - 592.

Blitz, JH. (2010). New Perspectives in Mississippian Archaeology. Journal of Archaeological Research 18, 1 - 39.

Bray, W. (2005). Crafts and Farmers: The Archaeology of the Yotoco Period. En: Cardale, M (Ed.). Calima and Malagana: Art and Archaeology in Southwestern Colombia [pp. 140-201]. Fundación proclaim, Bogotá.

Bray, W; Herrera, L; Cardale, M; Botero, P. y Monsalve, J. (1987). The Ancient Agricultural Landscape of Calima, Colombia. En: Denevan, W; Mathewson, K. y Knapp, G. (Eds.) Prehispanic Agricultural Fields in the Andean Region [pp.443 - 481]. Bar International Series, Oxford.

Brookfield, HC. (1984). Intensification Revisited. Pacific Viewpoint 25,15 - 44.

Brumfiel, E. y Earle, T. (1987). Specialization, Exchange, and Complex Societies: An Introduction. En: Specialization, Exchange, and Complex Societies, [pp. 1 9]. Cambridge University Press, Cambridge.

Carneiro, R. (1970). A Theory of the Origin of the State. Science 169 (3947), 733-738.

Carneiro, R. (1998). What Happened at the Flash Point? Conjectures of Chiefdom Formation at the Very Moment of Conception. En: Redmond, E. (Ed.) Chiefdoms and Chieftaincy in the Americas [pp.18 - 42]. University Press of Florida, Gainesville.

Clark, J y Blake, M. (1994). The Power of Prestige: Competitive Generosity and the Emergence of Rank Societies in Lowland Mesoamerica. En: Brumfiel, E. (Ed.) 
Factional Competition and Political Development in the New World, [pp.1730]. Cambridge University Press, Cambridge.

Cobb, C. (1996). Specialization, Exchange, and Power in Small-Scale Societies and Chiefdoms. Research in Economic Anthropology 17, 251 - 294.

D’Altroy, T y Earle, T. (1985). Staple Finance, Wealth Finance, and Storage in the Inka Political Economy. Current Anthropology 26, 187 - 206.

Delgado, F. (2002). Intensive Agriculture and Political Economy of the Yaguachi Chiefdom of the Guayas Basin, Coastal Ecuador. Disertación Doctoral sin publicar. Department of Anthropology, University of Pittsburgh.

Denevan, WM. (2001). Cultivated Landscapes of Native Amazonia and the Andes. Oxford University Press, Oxford.

Drennan, R. (1995). Chiefdoms in Northern South America. Journal of World Prehistory 9(3), 301 - 340.

Drennan, R. (1996). Betwixt and Between in the Intermediate Area. Journal of Archaeological Research 4(2), 95 - 131.

Earle, T. (1997). How Chiefs Come to Power: The Political Economy in Prehistory. Stanford University Press, Stanford.

Earle, T. y Doyel, D. (2008). The Engineered Landscapes of Irrigation. En: Cliggett, L. $\mathrm{y}$ Pool, C. Economies and the Transformation of Landscape. Altamira Press, A Division of Rowman Littlefield Publishers, Inc. New York, Toronto, Plymouth, Uk.

Erickson, C. (1993). The Social Organization of Prehispanic Raised Field Agriculture in the Lake Titicaca Basin. En: Scarborough, V. y Isaac, B. (Eds.) Economic Aspects of Water Management in the Prehispanic New World. Research in Economic Anthropology, Supplement No. 7 [pp. 369 - 426]. JAI Press, Greenwich, CT.

Erickson, C. (2006). Intensification, Political Economy, and the Farming Community: In Defense of a Bottom-Up Perspective of the Past. En: Marcus, J. y Stanish, C. (Eds.). Agricultural Strategies, [pp. 334 363]. Cotsen Institute of Archaeology, UCLA, Los Angeles.

Erickson, C. (2008). Amazonia: The Historical Ecology of a Domesticated Landscape. En: Silverman, H. y Isbell, W. (Eds.). Handbook of South American Archaeology [pp. 157-182]. Springer, New York.

Fisher, CT. y Feinman, GM. (2005). Introduction to Landscapes Over Time. American Anthropologist 107(1), 62 - 69.

Gassón, R. (1998). Prehispanic Intensive Agriculture, Settlement Pattern and Political Economy in the Western Venezuelan Llanos. Disertación Doctoral sin publicar. Department of Anthropology, University of Pittsburgh.

Gassón, R y Rey, JC. (2006). Cacicazgos cíclicos e intensificación agrícola en los Llanos Occidentales de Venezuela. En: Valdez, F. (Ed.). Agricultura ancestral camellones y albarradas [pp. 141 - 158]. Ediciones Abya-Yala. Ecuador.

Gilman, A. (2001). Assessing Political Development in Copper and Bronze Age Southeast Spain. En: Haas, J. (Ed.). From Leaders to Rulers [pp. 59 - 81]. Kluwer Academic/Plenum Publishers, New York. Gross, D. (1975). Protein Capture and Cultural Development in the Amazon Basin. American Anthropologist 77(3), 526 - 549. 
Hayden, B. (1995). Pathways to Power: Principles for Creating Socioeconomic Inequalities. En: Feinman, G. y Price, D. Foundations of Social Inequality [pp. $15-$ 86]. Plenum Press, New York.

Heckenberger, M. (2005). The Ecology of Power: Culture, Place, and Personhood in the Southern Amazon, A. D. 1000-2000. Routledge, New York \& Londres.

Johnson, G. (1982). Organizational Structure and Scalar Stress. En: Renfrew, C., Rowlands, M. y Abbott, B. (Eds.). Theory and Explanation in Archaeology [pp. 389 - 422]. Academic Press, London.

Kirch, P. (2006). Agricultural Intensification. A Polynesian Perspective. En: Marcus, J. y Stanish, C. (Eds.). Agricultural Strategies [pp. 191 - 217]. Cotsen Institute of Archaeology, UCLA, Los Angeles.

Knight Jr., VJ. y Steponaitis, VP. (1998). A New History of Moundville. En: Knight Jr., VJ. y Steponaitis VP. (Eds.). Archaeology of the Moundville Chiefdom [pp. 1 - 25]. Smithsonian Institution Press, Washington.

Lathrap, DW. (1970) The Upper Amazon. Praeger, New York.

Lepofski, D., Lertzman, K., Hallet, D. y Mathewes, R. (2005). Climate Change and Culture Change on the Southern Gulf Coast of British Columbia 2400-1200 ca. B.P.: An Hypothesis. American Antiquity 70, 267 - 293.

Meggers, B. (1992). Amazonia: real or counterfeit paradise? The Review of Archaeology, 13(2), 25 - 40.

Morey, N. (1975). Ethnohistory of the Colombian and Venezuelan Llanos. Disertación Doctoral sin publicar,
Department of Anthropology, University of Utah, Provo.

Morrison, K. (1994). The Intensification of Production: Archaeological Approaches. Journal of Archaeological Method and Theory 1, 111 - 159.

Myer, J. (2002). Characteristics of Mississippian Settlement in the Black Warrior Valley: Final Report of Season III of the Black Warrior Valley Survey. Presentado a Alabama Historical Commission, Project Number PT00SP180. Copias disponibles en Black Warrior Survey.

Netting, R. (1974). The System Nobody Knows: Village Irrigation in the Swiss Alps. En: Downing, E. y McGuire, G. (Eds.). Irrigation's Impact on Society [pp. 67 75]. University of Arizona Press, Tucson.

Netting, R. (1993). Smallholders, Householders: Farm Families and the Ecology of Intensive, Sustainable Agriculture. Stanford University Press, Stanford.

Nicholas, LM. (1989). Land Use in Prehispanic Oaxaca. En: Kowalewski, SA., Feinman, GM., Finsten, L., Blanton, RE. y Nicholas, LM. (Eds.). Monte Alban's Hinterland, Part II: Prehispanic Settlement Patterns in Tlacolula, Etla, and Ocotlán, the Valley of Oaxaca, Mexico, 1, [pp. 449 - 505]. Memoirs (23). Museum of Anthropology, University of Michigan, Ann Arbor.

Pebbles, CS. (1987). Moundville from 1000 to $1500 A$. D. as Seen from 1840 to 1985 A. D. En: Drennan, R. y Uribe, CA. (Eds.). Chiefdoms in the Americas [pp. 21 - 42]. University Press of America. Boston.

Redmond, E., Gassón, R. y Spencer, C. (1999). A Macroregional View of Cycling Chiefdoms in the Western Venezuelan Llanos. En: Bacus, E. y Lucero, L. (Eds.). Complex Polities in the Ancient Tropical 
World [pp. 109 - 130]. Archaeological Papers of the American Anthropological Association (9), Arlington.

Roosevelt, A. (1991). Moundbuilders of the Amazon: Geophysical Archaeology on Marajo Island, Brazil. Academic Press, San Diego.

Roosevelt, A. (1994). Amazonian Anthropology: Strategy for a New Synthesis. En: Roosevelt, A. (Ed.). Amazonian Indians from prehistory to the present: anthropological perspectives [pp. 1 -29]. Tucson, The University of Arizona Press.

Roosevelt, A. (1999). The Development of Prehistoric Complex Societies: Amazonia, A tropical Forest. En: Bacus, E. y Lucero, L. (Eds.). Complex Polities in the Ancient Tropical World, 9, 13 - 34. Archaeological Papers of the American Anthropological Association.

Rostain, S. (2008). Agricultural Earthworks on the French Guiana Coast. En: Silverman, H. y Isbell, WH. (Eds.). Handbook of South American Archaeology [pp. 217 234]. Springer, New York.

Saitta, D. (1994). Agency, Class and Archaeological interpretation. Journal of Archaeological Research 13, 201 - 227.

Salas, R. (2017). Arqueología del Paisaje Colores en el Valle de el Dorado Valle del Cauca - Colombia (100- 1550 D.C.). Universidad del Valle.

Sánchez, C. (2005). Constricción social y estrategias productivas agrícolas prehispánicas en el Alto Magdalena. Maguaré 19, 149 - 165.

Sánchez, C. (2007). Economía y sociedad prehispánica: El uso de la tierra en el Alto Magdalena. Bogotá: Banco de la
República, Fundación de Investigaciones Arqueológicas Nacionales.

Scarborough, VL. (2006). Intensification and the Political Economy: A Contextual Overview. En: Marcus, J. y Stanish, C. (Eds.). Agricultural Strategies [pp. 401 418]. Cotsen Institute of Archaeology, UCLA, Los Angeles.

Schaan, D. (2004). The Camutins Chiefdom: Rise and Development of Social Complexity on Marajó Island, Brazilian Amazon. Disertación Doctoral sin publicar. Department of Anthropology, University of Pittsburgh.

Schaan, D. (2009). Sobre os cacicados Amazonicos: sua vida breve e sua morte anunciada. Jangwa Pana 9, 45 - 64.

Smith, EA, y Jung-Kyoo, C. (2007). The Emergence of Inequality in Small Scale Societies: Simple Scenarios and AgentBased Simulations. En: Kohler, TA. y van del Leeuw, SE. (Eds.). The Model-Based Archaeology of Socionatural Systems [pp. 105 - 119]. Santa Fe, NM: School for Advanced Research.

Smith, NJ. (1995) Human-Induced Landscape Changes in Amazonia and Implications for Development. En: DiCastri, F. (Ed.). Global Land Use Change. A Perspective from the Columbian Encounter. Consejo Superior de Investigaciones Científicas, Madrid.

Spencer, C. (1993). Human Agency, Biased Transmission, and the Cultural Evolution of Chiefly Authority. Journal of Anthropological Archaeology 12, 41 - 74.

Spencer, C. (1994). Factional Ascendance, Dimensions of Leadership, and the Development of Centralized Authority. En: Brumfiel, EM. y Fox, JW. (Eds.). Factional Competition and Political 
Development in the New World [pp. 31 43]. Cambridge University Press, Cambridge.

Spencer, C. (1998). Investigating the Development of Venezuelan Chiefdoms. En: Redmond, EM. (Ed.). Chiefdoms and Chieftaincy in the Americas [pp. 104 137]. University of Florida Press, Gainesville.

Stanish, C. (2004). The Economy of Chiefdoms: An Economic Anthropological Model. En: Feinman, GM. y Nicholas, LM. (Eds.). Archaeological Perspectives on Political Economies [pp. 7 - 24]. The University of Utah Press, Salt Lake City.

Stanish, C. (2006). Prehispanic Agricultural Strategies of Intensification in the Titicaca Basin of Peru and Bolivia. En: Marcus, J. y Stanish, C. (Eds.). Agricultural Strategies [pp. 364 - 397]. Cotsen Institute of Archaeology, UCLA, Los Angeles.

Steponaitis, VP. (1978). Locational Theory and Complex Chiefdoms: A Mississippian Example. En: Smith, BD. (Ed.). Mississippian Settlement Patterns [pp. 417 -454]. Academic Press Inc., New York.

Steponaitis, VP. (1998). Population Trends at Moundville. En: Knight Jr., VJ. y Steponaitis, VP. (Eds.). Archaeology of the Moundville Chiefdom [pp. 26 - 43]. Smithsonian Institution Press, Washington.

Stone, GD. (1993). Agrarian Settlement and the Spatial Disposition of Labor. En: Holl, A.

Vargas, J. (2017). Complex Societies. Leadership and Agricultural Intensification in the Llanos Of Casanare, Colombia. Disertación Doctoral sin publicar, Department of Anthropology, University of Pittsburgh.

Walker, J. (2004). Agricultural Change in the Bolivian Amazon. Memoirs in Latin y Levy, T. (Eds.). Spatial Boundaries and Social Dynamics: Case Studies from Food-Producing societies [pp. 25 - 38]. Ann Arbor, Michigan: International Monographs in Prehistory.

Stone, GD. (1996). Settlement Ecology. The University of Arizona Press, Tucson.

Trawick, P. (2008). Reading History in an Irrigated Landscape: The Drama of the Commons in the Andes. En: Cliggett, L. y Pool, CA. (Eds.). Economies and the Transformation of Landscape [pp. 47 76]. Altamira Press. New York, Toronto, Plymouth, Uk

Thurston, T. (2006). The Barren and the Fertile: Central and Local Intensification Strategies across Variable Landscapes. En Marcus, J. y Stanish, C. (Eds.). Agricultural Strategies [pp. 131 - 161]. Cotsen Institute of Archaeology, UCLA, Los Angeles.

Vargas, J. (2011). Patrones de Asentamiento y Distribución de Recursos Agrícolas en Dos Unidades Políticas Prehispánicas en los Llanos Occidentales de Venezuela. Tesis de Maestría sin publicar. Instituto Venezolano de Investigaciones Científicas, Caracas.

Vargas, J. (2012). Patrones de Asentamiento y Distribución de Recursos Agrícolas en Dos Unidades Políticas Prehispánicas en los Llanos Occidentales de Venezuela. Maguaré 26(1), 195 - 228.

American Archaeology, 13. University of Pittsburgh. Pittsburgh.

Welch, PD. (1998). Outlying Sites within the Moundville Chiefdom. En: Knight Jr., VJ y Steponaitis, VP. (Eds.). Archaeology of the Moundville Chiefdom [pp. 133 - 166]. Smithsonian Institution Press, Washington 
Whitehead, N. (1994). The Ancient Amerindian Polities of the Amazon, the Orinoco, and the Atlantic Coast: A Preliminary Analysis of Their Passage from Antiquity to Extinction. En: Roosevelt, A. (Ed.). Amazonian Indians: From Prehistory to the Present [pp. 33 - 54]. University of Arizona Press, Tucson.

Zucchi, A y Denevan, W. (1979). Campos Elevados e Historia Cultural Prehispánica en los Llanos Occidentales de Venezuela. Instituto de Investigaciones Históricas, Universidad Católica Andrés Bello, Caracas. 